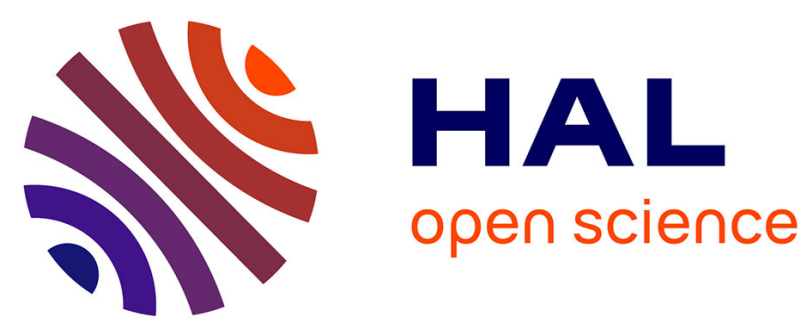

\title{
Improvement of capacitive performances of symmetric carbon/carbon supercapacitors by addition of nanostructured polypyrrole powder
}

Lynda Benhaddad, Jean Gamby, Lhaid Makhloufi, Alain Pailleret, Françoise Pillier, Hisasi Takenouti

\section{To cite this version:}

Lynda Benhaddad, Jean Gamby, Lhaid Makhloufi, Alain Pailleret, Françoise Pillier, et al.. Improvement of capacitive performances of symmetric carbon/carbon supercapacitors by addition of nanostructured polypyrrole powder. Journal of Power Sources, 2016, 307, pp.297-307. 10.1016/j.jpowsour.2015.12.007 . hal-01269658

\section{HAL Id: hal-01269658 \\ https://hal.sorbonne-universite.fr/hal-01269658}

Submitted on 9 Feb 2016

HAL is a multi-disciplinary open access archive for the deposit and dissemination of scientific research documents, whether they are published or not. The documents may come from teaching and research institutions in France or abroad, or from public or private research centers.
L'archive ouverte pluridisciplinaire HAL, est destinée au dépôt et à la diffusion de documents scientifiques de niveau recherche, publiés ou non, émanant des établissements d'enseignement et de recherche français ou étrangers, des laboratoires publics ou privés. 


\title{
Improvement of capacitive performances of symmetric carbon / carbon
}

\section{supercapacitors by addition of nanostructured polypyrrole powder}

\author{
L. Benhaddad ${ }^{\mathrm{a}, \mathrm{b}}$, J. Gamby ${ }^{\mathrm{b}}$, L. Makhloufia ${ }^{\mathrm{a}}$, A. Pailleret ${ }^{\mathrm{b},{ }^{*}, \text { F. Pillier }}{ }^{\mathrm{b}}$, H. Takenouti ${ }^{\mathrm{b}}$ \\ ${ }^{a}$ Laboratoire d'électrochimie, corrosion et de valorisation énergétique (LECVE). Département de Génie des \\ Procédés. A. Mira University, Route de Targa Ouzemmour, 06000 Bejaia, Algeria. \\ b- Sorbonne Universités, UPMC Univ. Paris 06, CNRS, Laboratoire Interfaces et Systèmes Electrochimiques \\ (LISE, UMR 8235), 4 place Jussieu, (case courrier 133), F-75005, Paris, France
}

\begin{abstract}
A nanostructured polypyrrole powder was synthesized in a previous work from the oxidation of pyrrole by a nanostructured $\mathrm{MnO}_{2}$ powder used simultaneously as an oxidizing agent and a sacrificial template in a redox heterogeneous mechanism. In this study, this original PPy powder was used as an active additive material with different ratio in carbon / carbon symmetrical supercapacitors whose performances were studied by cyclic voltammetry and electrochemical impedance spectroscopy (EIS) using a Swagelok-type cell. From the EIS spectra, the complex capacitance was extracted using a model involving two Cole-Cole type complex capacitances linked in series. The specific capacitance values evaluated by EIS and cyclic voltammetry are in a good agreement between them. The results show that the addition of nanostructured polypyrrole powder improves significantly the specific capacitance of the carbon electrode and consequently the performances of carbon/carbon supercapacitors. The original and versatile synthesis method used to produce this polypyrrole powder appears to be attractive for large scale production of promising additives for electrode materials of supercapacitors.

*Corresponding author. Tel: +33 (0)1 442741 69; fax: +33 (0)1 44274074 .

E-mail address: alain.pailleret@upmc.fr
\end{abstract}


Keywords: carbon/carbon supercapacitor, double-layer capacitance, polypyrrole, electrochemical impedance spectroscopy, swagelok, complex capacitance

\section{Introduction}

In recent years, electrochemical supercapacitors have attracted great attention because of their high capacitance and potential applications in energy storage. Electrochemical capacitors are indeed used to store the energy within the electrochemical double layer determined by the surface area and pore size distribution [1-3].

Activated carbon-based nanostructured materials with high specific surface areas are widely recognized as electrode materials for electric double-layer capacitors (EDLC). These products present outstanding properties, such as good electrical conductivity and stability, high accessible surface area, and reasonable cost [4-10]. Moreover, they can be produced in various forms, which allows the tuning of their porosity and their surface functionalization. Whether their electrical double layer is charged in aqueous or organic electrolytic solutions, their capacitance appears to be closely related to the surface area of the carbon/electrolytic solution interface. Moreover, it has been shown in literature over the last years that a good fit between their pore size and the size of electrolyte ions is beneficial for their performances. More accurately, it appears that $0.7-0.9 \mathrm{~nm}$ pore diameters are the most suitable for electrical double layer charging of pore walls with non-solvated ions in activated carbon materials. Even if additional mesopores interconnected with the abovementioned ultramicropores were shown to be beneficial for a good charge propagation, energy densities of carbon-based supercapacitors were often found to be lower than that of redox supercapacitors [5].

Recently, many research works have focused on additive electrode materials for supercapacitors, including conducting polymers and transition metal oxides to improve the capacitive performances of activated carbons [11-15]. In particular, many studies were focused on the synthesis and electrochemical characterisations of electronically conducting 
polymers, which represent promising electrode materials for the application of supercapacitors due to their high specific capacitance $[11,14,15]$. Among the conducting polymers, polypyrrole (PPy) is considered as an interesting material for supercapacitor electrodes due to its high conductivity, good redox reversibility, long-term environmental friendliness, low cost, and easy chemical or electrochemical synthesis [16,17]. Chemical synthesis of conducting polymers is simply achieved by oxidation of corresponding monomers using an oxidizing agent and thus is well adapted for mass-production in industry as it provides a cheap and efficient route $[18,19]$. Compared to bulk conducting polymers, nanostructured conducting polymers are expected to exhibit improved performances in technological applications because some unique properties may arise from their nanoscale morphology [20]. Conducting polymer nanotubes and nanowires with diameters less than 100 $\mathrm{nm}$ can be made by hard templates such as porous polycarbonate films [21], or porous alumina [22], which usually have to be removed after synthesis of PPy nanostructures. Nevertheless, this route appears to be risky as it may damage the synthesized PPy structures due to the use of strong acid/alkaline aqueous solutions, organic solvents, or elevated temperatures. On the other hand, soft templates such as reverse microemulsions [23] or micelles [24] may have the disadvantages of instability, low efficiency, and lack of versatility.

The conducting polymers are used in different electrolytes to obtain a higher specific capacitance. For example, the best electrolytes for polyaniline are usually acidic solutions [25], whereas polypyrrole and polythiophene exhibit ideal capacitance behaviour in neutral and basic electrolytes [26]. Aqueous electrolytes are mostly composed of small inorganic anions (angström level) that can easily access the micropores and mesopores under an electric field. In this regard, aqueous electrolytes seem to be most favourable for pairing with micropores activated carbons for supercapacitors. Indeed, it was reported that after prolonged operation, supercapacitors based on activated carbons and organic electrolytes may reveal 
capacity fading and resistance increase, together with microscopic phenomena such as gas evolution, increase of the electrode mass or local disbonding of the coating layer from the metallic collector [27]. There is however contributions from functional surface groups, which are in general present on activated carbons and can be charged and discharged, giving rise to a pseudocapacitance [28].

Polypyrrole and carbon materials have already been associated frequently to produce competitive composite materials for supercapacitor electrodes (see a non-exhaustive list in Table 1). Our objective was thus to benefit from a simple and efficient chemical method that was developped in our group to synthesize nanostructured PPy powders by using manganese dioxide as oxidizing agent and nanostructured template in presence of pyrrole [35]. In the work reported hereafter, the PPy powder thus obtained was used as active additive in carbon / carbon supercapacitors to improve their performances. The study of the capacitive performances of added PPy to activated carbon powder was carried out by cyclic voltammetry (CV) and electrochemical impedance spectroscopy (EIS) techniques.

$$
<\text { Table } 1>
$$

\section{Experimental}

\subsection{Chemicals}

All the solutions were prepared using deionised water with double ion exchange columns. Sulphuric acid $\left(\mathrm{H}_{2} \mathrm{SO}_{4}\right)$ and ethanol $\left(\mathrm{C}_{2} \mathrm{H}_{5} \mathrm{OH}\right)$ were purchased from Prolabo. Pyrrole was purchased from Fluka ( $97 \%$ purity) and was purified by distillation before use. Picactif BP $10^{\mathrm{TM}}$ (hereby referred to as PICA) is commercially available activated carbon, and was used as received. Its nominal specific surface area was $2000 \mathrm{~m}^{2} \mathrm{~g}^{-1}$. The characterization of PICA by different physical techniques was realized by different research groups $[9,10,36]$. 


\subsection{Nanostructured polypyrrole powder}

The chemical synthesis and the characterization of this powder has already been reported in a previous publication [35]. It consisted of a hydrothermal synthesis of $\mathrm{MnO}_{2}$ powder [37,38] followed by the polymerization of pyrrole using $\mathrm{MnO}_{2}$ simultaneously as oxidizing agent and template. The polypyrrole powder was chemically prepared by injecting liquid pyrrole $(0.2 \mathrm{M})$ into a beaker containing $\mathrm{MnO}_{2}$ powder $(2 \mathrm{~g})$ suspended in a $\mathrm{H}_{2} \mathrm{SO}_{4}$ $(100 \mathrm{~mL}, 1 \mathrm{M})$ aqueous solution at room temperature. The mixture was stirred with magnetic bar for 1 hour at room temperature. The black precipitate of polypyrrole was collected by filtration, rinsed repeatedly with deionised water, and finally dried at $60{ }^{\circ} \mathrm{C}$ for $24 \mathrm{~h}$.

\subsection{Electrochemical tests}

The PICA electrode was prepared by mixing $95 \%$ (in mass) PICA and $5 \%$ PTFE into $5 \mathrm{~mL}$ of ethanol (95\%). The PICA/PPy composite electrodes were prepared, unless described differently, by mixing $85 \%$ PICA, $10 \%$ PPy, and $5 \%$ polytetrafluoroethylene (PTFE) into 5 $\mathrm{mL}$ of ethanol (95\%). After evaporation of ethanol, these mixtures were pressed in a roller and dried at $120^{\circ} \mathrm{C}$ for $24 \mathrm{~h}$. A 1.5 to $1.8 \mathrm{~mm}$ thick soft film was then obtained. A disk of 0.6 $\mathrm{cm}$ in diameter was then cut out by punching. The frontal surface area was thus $0.29 \mathrm{~cm}^{2}$. The disk thus obtained weighed about $8 \mathrm{mg}$.

The electrochemical behaviour of these electrodes was evaluated using CV and EIS techniques. All electrochemical experiments were carried out by using the Swagelok-type device presented in Figure SI-1a. Two active materials based disk electrodes were set together with a separator made of a filter paper between them as illustrated in Figure SI-1b.

They were then inserted into a stainless-steel tube of the Swagelok-type cell. The electrical isolation of the electrodes to the cylinder was ensured by a $100 \mu \mathrm{m}$-PET (polyethylene terephthalate) sheet. Two cylinders push the electrodes towards the centre of 
the tube by means of two nuts to make electrical contact. The PET spacers set on each cylinder wall allowed the electrical isolation to the central tube. A small plug set at the extremity of each cylinder was used to connect the potentiostat.

The electrochemical tests were carried out with the help of two active material based pellets possessing close masses and separated by a filter paper impregnated with the $1 \mathrm{M}$ $\mathrm{NaNO}_{3}$ aqueous electrolytic solution.

The $\mathrm{CV}$ tests were performed in the potential window extending from -0.4 to $0.6 \mathrm{~V}$ (vs. open-circuit potential, $E_{\mathrm{OC}}$ ) using a Bio-logic SP 300 potentiostat controlled by the ECLab V10.11 software.

The EIS measurements were performed using Dielectric interface Solartron 1260 gain phase impedance analyzer coupled with a frequency response analyser (FRA 1255) and computer-controlled (Smart software, Solartron Analytical). A Swagelok type supercapacitor device was connected to a dielectric interface apparatus. An ac-amplitude of $100 \mathrm{mV}_{\text {rms }}$ was applied and data were collected in the frequency range from $100 \mathrm{kHz}$ to $1 \mathrm{mHz}$ with 5 points per decade.

\subsection{Instruments}

A FEG-SEM (Ultra 55 Zeiss) coupled with EDX analysis was used to observe the synthesized powders. In addition to these techniques, XRD and TEM techniques were also used. The TEM images were obtained with a JEOL 2000 FX microscope running at an accelerating voltage of $200 \mathrm{keV}$. Prior to analysis, the powders were crushed in a mortar. A small amount of this powder was then added in a small volume of ethanol using ultrasonic bath. A drop of this mixture was then placed on a copper grid covered with a carbon coating and dried in air before analysis. 


\section{Results and Discussion}

\subsection{Characterization of polypyrrole powder}

The morphology of the PPy powder resulting from the synthesis method published previously by us [35] was observed by FEG-SEM (Figure 1a). This picture shows that the synthesized PPy particles exhibit a hollow sea urchin like morphology dictated by that observed for $\mathrm{MnO}_{2}$ powders [35] with a rather uniform size and a more or less widely open mouth. Elemental analysis by EDX (Figure 1b) confirms the presence of carbon and nitrogen, elemental components of PPy, in the structure of the synthesized powders. The presence of sulphur and oxygen is also obvious in this PPy powder suggesting at this stage, that the obtained PPy is likely doped by $\mathrm{SO}_{4}{ }^{2-}$ anions present in the synthesis solution, and consequently, that PPy is in an oxidised state. It is worth noting the complete absence of manganese in the PPy powder in spite of the use of $\mathrm{MnO}_{2}$ as an oxidizing agent for pyrrole polymerization. From these first observations, it can be concluded that hollow particles of nanostructured PPy were successfully synthesized by a chemical route.

\section{$<$ Figure $1>$}

The PPy particles observed in Figure 1a are in fact nanotubes according to TEM image (Figure 1c). Typical TEM image shows that the PPy nanotubes powder synthesized from nanostructured $\mathrm{MnO}_{2}$ powders possess a typical outer diameter of ca. $70 \mathrm{~nm}$, a length up to $400 \mathrm{~nm}$, and an inner diameter of ca. $20 \mathrm{~nm}$, which vary along the nanotube. One can also distinguish, especially from Figure 1c, that those nanotubes are also closed at one extremity.

The XRD pattern of the PPy powder is displayed in Figure 1d. Since no manganese was present in this material, the XRD pattern can be ascribed only to PPy. This XRD spectrum exhibits a weak and broad diffraction peak at $2 \theta=25^{\circ}$, which has already been encountered in literature and attributed to amorphous PPy structures $[39,40]$. 


\subsection{Electrochemical results}

\subsubsection{Comparison of the specific capacitance of PICA and PICA/PPy electrodes}

\section{Cyclic voltammetry}

Typical cyclic voltammograms (CVs) were recorded for PICA and PICA/PPy electrodes between -0.4 and $0.6 \mathrm{~V}$ versus $E_{\mathrm{OC}}$ with a scan rate $v=2 \mathrm{mV} \mathrm{s}^{-1}$ (cf. Figure 2a). Both CVs possess an almost rectangular shape revealing an ideal supercapacitor behaviour with nearly constant current in the whole potential range. In this figure, it can be noted that PPy powder added to the active carbon (PICA/PPy) makes the current higher, indicating that the resulting composite material has a greater specific capacitance.

\section{$<$ Figure $2>$}

The capacitance of an electrode as a function of potential, $C(E)$, may be defined by the following relation:

$$
C(E)=\frac{2 \cdot I(E)}{v \cdot m}
$$

Where $m$ is the mass of an electrode $(g), E$ the potential $(\mathrm{V}), I(E)$ the current (A) at $E$, $v$ the potential sweep rate $\left(\mathrm{mV} \mathrm{s}^{-1}\right)$, and the factor 2 is due to the fact that the two electrodes were linked in series. The software used (Bio-logic EC-Lab V10.11) permits the calculation of the electrical charge $Q$ (in $\mathrm{A}$ h) as a function of potential in the form of straight line whose slope $(\mathrm{d} Q / \mathrm{d} E)$ allows the determination of the specific capacitance value $\mathrm{C}\left(\mathrm{F} \mathrm{g}^{-1}\right)$ as follows:

$$
C=\frac{2 \cdot \text { slope } \cdot 3600}{m}
$$

The capacitance values were determined as a function of the cycle number $n_{\text {cyc }}$, and the results are presented in Figure $2 \mathrm{~b}$. This figure shows that the specific capacitance of these electrodes remains essentially constant, at least up to 50 cycles. Besides, it increases by more than $50 \%$ when the electrode contains $10 \%$ in mass of PPy powder. This indicates that the 
presence of PPy improves markedly the capacitance performance of the carbon electrode (PICA). According to literature, the contact resistance between carbon particles induces a loss of capacitive performance of the supercapacitor [41]. The PPy addition may thus improve the electrical contact between particles.

\section{Electrochemical Impedance Spectroscopy}

The PICA and PICA/PPy electrodes were submitted to $10 \mathrm{CV}$ scans between -0.4 and $0.6 \mathrm{~V}$ vs. $E_{\mathrm{OC}}$ at $2 \mathrm{mV} \mathrm{s}^{-1}$, and then the EIS measurements were carried out.

The impedance spectra obtained experimentally are normalized with respect to the electrode mass. Figure 3 shows the impedance spectra of two electrodes (see blue triangles and red circles) and highlights a capacitive behaviour in the whole frequency domain, and composed of:

- At the high frequency limit, the response includes the electrolyte resistance through the separator (filter paper) inserted between the two disks of active materials and the contact resistance at the current collector/active material interface [42]. The current collectors are metallic, thus their resistance is negligible. The electrolyte resistance through the active materials is shunted by electronically conducting active materials. However, the contact resistance between active material particles is electronic, therefore this resistance will be added to $R_{\mathrm{s}}$.

- When the frequency decreases ( $f>100 \mathrm{~Hz}$ ), a semicircle due to the charge transfer resistance in parallel with an interface capacitance was observed.

- For intermediate frequency range (10 to $0.1 \mathrm{~Hz}$ ), a straight line with an angle close to $45^{\circ}$ with the real axis was observed. This behaviour can be allocated to two different origins; diffusion of ions from the electrolyte to the interior of the electrode (Warburg impedance), or the potential distribution through the porous active material (De Levie impedance). This behaviour will be discussed below to determine its physical origin. 
- At low frequency ( $\mathrm{f}<0.1 \mathrm{~Hz}$ ), a straight line almost parallel to the imaginary axis was observed which characterize the insertion/expulsion of charged species of reversible systems [43].

$$
<\text { Figure } 3>
$$

It can be clearly observed that the semicircle diameter and the length of the $45^{\circ}$ line decrease, in the presence of PPy in the composite electrode, indicating the decrease of the charge transfer resistance and ions diffusion resistance [44] or the resistance through the active materials for the De Levie model. The decrease of the real part for a given frequency corresponds to a lower energy loss by Joule effect during the charge/discharge cycle thus giving rise to higher energy efficiency.

The two proposed models that may explain the impedance spectra will be separately discussed below.

\section{A. Application of diffusion impedance}

In this model, the impedance is presented by the following equation where the charge transfer resistance $R_{\mathrm{t}}$ (in $\Omega \mathrm{cm}^{2}$ or $\Omega \mathrm{g}$ ) is linked in parallel with the double layer capacitance $C_{\mathrm{d}}\left(\right.$ in $\mathrm{F} \mathrm{cm}^{-2}$ or $\left.\mathrm{F} \mathrm{g}^{-1}\right)$.

$$
Z=R_{\mathrm{s}}+\frac{1}{\frac{1}{R_{\mathrm{t}}+Z_{\mathrm{D}}}+C_{\mathrm{d}}(\mathrm{j} \cdot \omega)^{\mathrm{n}_{\mathrm{C}}}}
$$

Where $\omega$ is the sinusoidal pulsation $\left(\operatorname{rad~s}^{-1}\right)$ and $Z_{\mathrm{D}}$ is the restricted diffusion impedance (in $\Omega \mathrm{cm}^{2}$ or $\Omega \mathrm{g}$ ) [45].

$$
Z_{\mathrm{D}}=\frac{\mathrm{R} \cdot T}{n^{2} \cdot \mathrm{F}^{2} \cdot A \cdot \sqrt{D} \cdot C} \frac{\operatorname{coth}\left[\frac{\delta}{\sqrt{D}} \sqrt{(\mathrm{j} \cdot \omega)^{\mathrm{n}_{\mathrm{D}}}}\right]}{\sqrt{(\mathrm{j} \cdot \omega)^{\mathrm{n}^{\mathrm{D}}}}}
$$


Where R stands for the gas constant $\left(8.31 \mathrm{~J} \mathrm{~K}^{-1} \mathrm{~mol}^{-1}\right), T=298 \mathrm{~K}, \mathrm{~F}=96500 \mathrm{C} \mathrm{mol}^{-1}$, $D$ the diffusion coefficient $\left(\mathrm{cm}^{2} \mathrm{~s}^{-1}\right), C$ the concentration of diffusing species $\left(\mathrm{mol} \mathrm{cm}^{-3}\right)$, and $\delta$ is a characteristic diffusion length $(\mathrm{cm})$.

In this calculation, the impedance in $\Omega \mathrm{cm}^{2}$ is presented with the electrode frontal area so that the magnitude of each parameter can be readily compared to those of common use. Figure SI-2 shows the comparison between the experimental results and those obtained by a parameter regression calculation with a Simplex method. One can observe in this figure a very satisfactory agreement between the experimental results and those calculated by the fitting procedure. In a first approach, these results seem to validate the diffusion model. They must be examined in more details with the values of various obtained parameters listed in Table 2. In this calculation, the concentration of the diffusing species is set to $1 \mathrm{M}$ (that corresponds to $10^{-3} \mathrm{~mol} \mathrm{~cm}^{-3}$ ).

$<$ Table $2>$

In this table, the mean deviation, $\chi(\%)$, between experimental and calculated impedance spectra was evaluated from chi-square by:

$$
\chi^{2}(\%)=\frac{100}{2 \cdot n_{F}-8} \cdot \sum_{i=1}^{n_{F}}\left[\left(\frac{\operatorname{Re}(\exp )_{\mathrm{i}}-\operatorname{Re}(\text { calc })_{\mathrm{i}}}{\left|Z_{\mathrm{i}}\right|}\right)^{2}+\left(\frac{\operatorname{Im}(\exp )_{\mathrm{i}}-\operatorname{Im}(\text { calc })_{\mathrm{i}}}{\left|Z_{i}\right|}\right)^{2}\right]
$$

In this equation, $n_{\mathrm{F}}$, is the number of frequencies defining the impedance spectra (41 in these experiments), " 8 " is the number of variables thus $\left(2 \cdot n_{\mathrm{F}}-8\right)$ represents the degree of freedom. $\left|Z_{\mathrm{i}}\right|, \mathrm{Re}$, Im stand respectively for impedance modulus, and the real and imaginary components, whereas "exp" and "calc" indicate experimental and calculated data. A value of 1 for $\chi$ indicates that the experimental points are scattered by $1 \%$ from the theoretical value.

The $\chi$ values are $2.6 \%$ for both spectra. This relatively large $\chi$ value is due to the fact that the experimental points observed at low frequencies $(\mathrm{f}<0.1 \mathrm{~Hz})$ scattered slightly more 
than those in higher frequency domains. Taking this remark into account, the deviation observed is reasonable. It is important to emphasise that there is no systematic deviation indicating the adequacy of the model. The obtained value for the double layer capacitance (25 $\sim 30 \mu \mathrm{F} \mathrm{cm}^{-2}$ ) indicates that the interface was located between the separator and the active materials, thus the diffusion, if any, occurs in normal component, i.e. in the electrode thickness, and not in radial component, inside pores. The diffusion coefficient $(D)$ is almost 4 orders of magnitude smaller than for diffusion of ions in an aqueous medium. That may be explained by the diffusion through the solid phase. In contrast, the diffusion layer thickness $(\delta)$ is 3 orders of magnitude too small for a diffusion taking place through the entire electrode thickness. Despite the good reproduction of the experimental impedance spectra, as illustrated in Figure SI-2, it is less probable that the diffusion process accounts correctly the impedance spectrum obtained with PICA or PICA/PPy electrodes.

\section{B. Porous electrode Model}

The experimental impedance spectra displayed in Figure 3 may be explained also by the porous electrode behaviour. The observed line whose slope is close to $45^{\circ}$ can then be assigned to the potential and current distribution perpendicular to the disk surface. For frequencies above $100 \mathrm{~Hz}$, the presence of a capacitive loop is presented by the parallel connection of a resistance $R$ and a capacitor $C$ or a constant phase element $Q$. It is important to note that this part of the impedance is not noticeably flattened in the Nyquist diagram, indicating that this contribution is external to the porous texture of the disk. This contribution is therefore located at the interface between the paper filter and PICA or PICA/PPy disk, because the current flow at the contact between the current collector and the disk is electronic,

so there will be no space charge. The equivalent circuit is illustrated in Figure 4. Recall that the same explanation was given about the $C_{\mathrm{d}} / R_{\mathrm{t}}$ couple for diffusion model.

\section{$<$ Figure $4>$}


The De Levie model [46] is based on a hollow cylinder where the inner pore wall constitutes the electrochemical interface and the local potential at the pore wall is governed by the ohmic drop through the cylinder. Many cylinders may be linked in parallel. This model is not realistic for the present case, since the electrode was constituted of the compressed mixture of active carbon and PPy powder. An alternative mathematical approach allows extending it to the continuum model [47]. The active material is considered homogeneous and the local potential is distributed in its bulk.

The overall impedance can be expressed by the following equation :

$$
Z=R_{\mathrm{s}}+2 \cdot Z_{\mathrm{rt}}+2 \cdot Z_{\mathrm{p}}
$$

where $Z_{\mathrm{p}}$ is the impedance of a porous electrode and it can be expressed as follows:

$$
\begin{aligned}
& Z_{\mathrm{p}}=\sqrt{R_{0} \cdot Z_{0}} \cdot \operatorname{coth}\left(\frac{L}{\lambda}\right) \\
& \text { Where } \lambda=\sqrt{\frac{Z_{0}}{R_{0}}}
\end{aligned}
$$

Here $\lambda$ is the penetration depth, $Z_{0}$ is the impedance corresponding to the charge storage reaction for the unit depth $(\Omega \mathrm{cm}), R_{0}$ is the resistance of ionic conduction through the active material of the unit depth $\left(\Omega \mathrm{cm}^{-1}\right)$, and $L$ is the thickness of the disk electrode $(\mathrm{cm})$.

The impedance $Z_{0}$ corresponding to the storage of electricity in the active material is represented by a constant phase element $(\mathrm{CPE})$ :

$$
Z_{0}=\frac{1}{Q_{0} \cdot(\mathrm{j} \cdot \omega)^{\mathrm{a}}} ; \omega=2 \cdot \pi \cdot f
$$

Here, $f$ is frequency in $\mathrm{Hz}\left(\mathrm{s}^{-1}\right)$. At the disk/ filter paper interface, appears the impedance of a planar electrode $Z_{\mathrm{rt}}$.

$$
Z_{\mathrm{rt}}=\frac{R_{\mathrm{t}}}{1+\left(j \cdot \omega \cdot R_{\mathrm{t}} \cdot C_{\mathrm{d}}\right)^{\mathrm{a}_{\mathrm{t}}}}
$$


Where $R_{\mathrm{t}}$ and $C_{\mathrm{d}}$ have the same meaning as above.

The comparison of the experimental spectra and those obtained by regression calculation is displayed in Figure 3. For this figure, the impedance spectra were presented with respect to the sample mass for one disk. The values of various parameters evaluated by non-linear regression calculation with a simplex algorithm for single disk are shown in Table 3.

$<$ Table $3>$

Operations used to evaluate some variables are presented below.

$Q=Q_{0} \cdot L$

$Q_{0}$ is the CPE element for the unit length of the disk.

The value of $R_{\mathrm{L}}$ corresponding to the resistance of $45^{\circ}$ linear part is calculated by:

$R_{\mathrm{L}}=\frac{L \cdot R_{0}}{3}$

As we have noted previously in Figure 3, the decrease of the semicircle diameter for the PICA/PPy composite electrode results from the decrease of the resistances at the active material/separator interface. Thus, the presence of PPy in the composite electrode improves significantly the charge transfer between the filter paper and disk. The resistance value of ionic conduction in the active material, $R_{0}$, of PICA/PPy is more than twice smaller. This decrease of $R_{0}$ results directly in the diminishing of $R_{\mathrm{L}}$. The real part component, the cell resistance $R_{\text {total }}\left(=R_{\mathrm{s}}+R_{\mathrm{t}}+R_{\mathrm{L}}\right)$, associated with the charge/discharge impedance $Z_{0}$, is important in the functioning of the supercapacitor since this term corresponds to the energy loss by Joule effect during the charge and discharge processes as mentioned above. Ideal capacitor should have no real part. 


\section{Complex capacitance}

The electrochemical impedance spectroscopy presented in the Nyquist diagram (Figure 3) however supplies no direct quantitative information about the capacitive behaviour as a function of the frequency of the supercapacitor. In the presence of resistive contribution, the current flow is split into two components, one for charging/discharging of the capacitance, and another to the energy loss by Joule effect. Access to this information can be obtained by using the complex capacitance which considers supercapacitor as an element whose value depends upon the frequency $[48,49]$. If one considers that the complex capacitance depending on the pulsation $\omega$, from the electrochemical impedance $Z(\omega)$, one yields readily:

$$
Z(\omega)=\frac{1}{\mathrm{j} \cdot \omega \cdot C(\omega)}
$$

However, the overall impedance $Z$ measured experimentally contains the solution resistance $R_{\mathrm{s}}$, thus:

$$
Z=R_{\mathrm{S}}+Z(\omega)
$$

Therefore, the complex capacitance $C^{*}(\omega)$ can be deduced according to the following equation:

$$
C *(\omega)=\frac{1}{\mathrm{j} \cdot \omega \cdot\left[Z(\omega)-R_{\mathrm{S}}\right]}
$$

This complex capacitance can be represented by the real and imaginary components:

$$
C^{*}(\omega)=C^{\prime}(\omega)+C^{\prime \prime}(\omega)
$$

With :

$C^{*}(\omega)$ : Complex capacitance depending on frequency $\left(\mathrm{F} \mathrm{cm}^{-2}\right.$ or $\left.\mathrm{F} \mathrm{g}^{-1}\right)$,

$C^{\prime}(\omega)$ : Real part of the complex capacitance. The low frequency limit of this term corresponds to the cell capacitance $\left(\mathrm{F} \mathrm{cm}^{-2}\right.$ or $\left.\mathrm{F} \mathrm{g}^{-1}\right)$, 
$C^{\prime \prime}(\omega)$ : Imaginary part of the complex capacitance. It corresponds to the energy dissipation due to the resistances of the system $\left(R_{\mathrm{t}}\right.$ and real component of $Z$ due to the CPE behaviour) ( $\mathrm{F} \mathrm{cm}^{-2}$ or $\left.\mathrm{F} \mathrm{g}^{-1}\right)$.

As the cell is composed of two identical cells linked in series, the overall capacitance $C^{*}(\omega)$ can be calculated as follows [50]:

$$
C^{*}(\omega)=\frac{C_{1}(\omega)}{2}=\frac{C_{2}(\omega)}{2}
$$

Figure 5a shows the modulus of the complex capacitance as a function of the frequency for the two electrodes PICA and PICA/PPy whereas Figure 5b depicts their spectrum in complex plane. At the low frequency limit, as stated above, the modulus of the complex capacitance corresponds to the effective specific capacitance stored in the cell.

\section{$<$ Figure $5>$}

Regression calculations with a single relaxation time constant of complex capacitance did not allow correctly reproducing the experimental $C^{*}(\omega)$ as can be guessed by a slightly asymmetric shape of the complex capacitance in Figure 5b. Therefore, two relaxation phenomena were introduced and each one follows the Cole-Cole type relaxation process:

$$
C^{*}(\omega)=C_{0}+\frac{C_{1}}{1+\left(\mathrm{j} \cdot \omega \cdot \tau_{1}\right)^{a_{1}}}+\frac{C_{2}}{1+\left(\mathrm{j} \cdot \omega \cdot \tau_{2}\right)^{a_{2}}}
$$

The results of regression calculation by a Simplex method are displayed in Table 4 .

$$
<\text { Table } 4>
$$

It can be noticed that the low frequency limit $C^{*}(0)$ i.e. $C_{0}+C_{1}+C_{2}$ is in agreement with the values obtained by CV. As for $Q$ value listed in Table 2, it is important to note that $Q$ is the CPE parameter and its value corresponds to the capacity at the angular frequency $\omega$ 
equal to 1. By applying Brug's equation [51] in our particular case, the effective capacitance $C$ according to the following equation can be determined, as follows:

$$
C=\left[Q \cdot\left(\frac{1}{R_{\mathrm{S}}+R_{\mathrm{t}}+R_{\mathrm{L}}}\right)^{1-a}\right]^{\frac{1}{a}}
$$

One gets the value of 106 and $166 \mathrm{Fg}^{-1}$ for PICA and PICA/PPy electrodes, respectively. These values are found in good agreement with the values of $C_{\text {total }}$ (Table 4).

A good agreement between these three different methods validates the analytical methods used. We recall that the complex capacitance of PICA/PPy electrode is higher than data determined for the PICA electrode. We can also notice that $\tau_{2}$ corresponds approximately when all the active material is solicited by ac signal, i.e. $L / \lambda \approx 1$. As for $\tau_{1}$, it corresponds to the transition from the porous to the expanded electrode behaviour.

In conclusion, the addition of PPy powder to the activated carbon (PICA) improves significantly the performance of the PICA / PICA supercapacitors. As already mentioned earlier, the contact between the carbon particles induces an internal resistance and therefore decreases the performances of the supercapacitor [41]. The PPy synthesized in the present study is a mixed conductor, electronic and ionic, and it is porous. Therefore, the introduction of this PPy powder in the activated carbon can improve the capacitance of the supercapacitor thanks to its conductivity by allowing better electronic contact between particles. Obviously, nanostructured PPy powder supplies also its own pseudo-capacitive contribution.

\subsubsection{The ageing effect}

Figure $2 \mathrm{~b}$ showed that the specific capacitance determined by $\mathrm{CV}$ does not significantly change with the 50 first cycles. We actually verified that this observation 
remains valid over a very large number of consecutive CV scans, (i.e. 1000 scans, see Figure SI-3) and EIS investigations (see Figure 6).

$<$ Figure 9>

The plateau current decreases only slightly with the cycle number, thus there is a weak ageing effect. In contrast, the initial slope of cycling voltammogram becomes gentler with cycling, indicating the increase of overall internal resistance. The capacitance with respect to cycle number was calculated by the current at $E_{O C}$ as the mean value from the forward and backward scan.

$$
C=I_{E_{O C}} \frac{d t}{d E}
$$

Figure 6a shows the impedance spectra obtained after various CV scan numbers and Figure $6 \mathrm{~b}$, the capacitance calculated according to Equation 20. The capacitance decreases significantly above 500 cycles, but it is uncertain if the increase of internal resistance affects the calculated value. This is the reason why we verified this result by EIS measurements.

$$
<\text { Figure } 6>
$$

On figure $6 a$, it can be noticed that the imaginary part of the low frequency limit increases only slightly indicating that the specific cell capacitance may decrease but only a little. The most marked fact is related to the real part that becomes greater with increasing cycle numbers. As can be seen in the insert, even the high frequency limit, i.e. $R_{\mathrm{s}}$, the solution resistance determined through the filter paper increases. This effect may be explained by the fact that the electrolyte in the filter paper diffuses into the PICA/PPy material. These spectra were analyzed with the porous electrode model as mentioned above, and the results of regression calculation by the Simplex method are displayed in Table 5.

$<$ Table $5>$ 
The resistances $R_{\mathrm{s}}$ and $R_{0}$ increased about two times after 1000 cycles compared with the initial value whereas $R_{\mathrm{t}}$ is multiplied by seven. As a whole, the cell resistance $R_{\text {total }}$ becomes about five times greater. The effective specific capacitance likely remains almost constant by potential cycling up to 1000 times, whereas the energy efficiency will decrease significantly. This result contrasts to the assertion made in literature [40].

In order to check how the effective capacitance changes with the cycling, the complex capacitance was calculated from the impedance spectra presented above, and then regression calculations as explained above were carried out with two time constants for the capacitance relaxation process.

The results of fitting procedure are given in Table 6 . It can be seen that $C_{0}$ and $C_{1}$ decrease whereas $C_{2}$ varies little. Since the latter determines essentially the effective cell capacitance, it remains constant by ageing induced by potential cycling except for the largest cycle. The variation is more marked for the relaxation time constants, as both $\tau_{1}$ and $\tau_{2}$ increase significantly, that is, the relaxation process becomes slower and slower.

$$
<\text { Table } 6>
$$

A decrease of the capacitance observed by the cyclic voltammetry is thus due to the increase of the relaxation time constant, $t_{2}$, leading to the too fast $2 \mathrm{mV} \mathrm{s}^{-1}$ scan rate. The capacitance evaluated from EIS measurements were overlaid in Figure $6 \mathrm{~b}$. The values evaluated by EIS determined from the extrapolation to zero frequency are systematically greater as expected. The increase of $R_{S}$ may be explained by the drying of filter paper and this phenomenon also leads to an increase of $R_{t}$ value. Since the ageing effect was examined, we will now focus on the examination of the effect of PPy content of the composite electrode on the supercapacitor performance. 


\subsubsection{Effect of the PPy mass in PICA/PPy electrode}

In addition to PICA/PPy examined above, composite materials containing 30, 60, and $70 \%$ in mass of PPy powder were prepared. The other preparations and experimental conditions described above were the same.

\section{Cyclic voltammetry}

The CV obtained for the composites containing different PPy masses is displayed in Figure SI-4. The current intensity is normalized with respect to the mass of one disk electrode.

It can be noticed that these voltammograms display an almost rectangular shape indicating the capacitive behaviour of the electrodes. It can be noticed also that the plateau current observed on these voltammograms increases with the polypyrrole content in the PICA/PPy composite electrode. This indicates an increase of the specific capacitance of the electrode and therefore an improvement of the supercapacitor performances. Indeed, the current plateau is narrower for PICA/PPy electrodes whose PPy content is 60 or $70 \%$ of the total mass of the electrode. A fast current increase in absolute value for potentials more positive than $0.4 \mathrm{~V}$ and more negative than $-0.3 \mathrm{~V}$ are partly ascribed to a pseudo-capacitive behaviour, due to a reversible oxidation / reduction of the polymer. It can be remarked that the initial slope of the voltammogram becomes steeper when PPy content increases, that is, the internal resistance of PICA / PPy decreases with addition of PPy in the active material. As expected, the use of conducting polymers permits a neat improvement of carbon/carbon supercapacitor performances but their major drawback may be their instability. Hence, the maximum useful potential range for the PICA/PPy electrode with high PPy content is below $0.7 \mathrm{~V}$ 
Since excessive addition of nanostructured PPy powder may be harmful for the stability of the electrode, the effect of cycle number on the specific capacity was investigated. The results are shown in Figure SI-5.

This figure shows first that the specific capacitance of the electrodes increases with the increase of the PPy content in the composite film as observed in Figure SI-4. However, the composite electrode with the PPy content of 60 or $70 \%$ of total active mass revealed the decrease in specific capacity up to $10^{\text {th }}$ cycles due to the faradic reactions of PPy. Above this cycle number, the specific capacitance tends to stabilize.

\section{Electrochemical Impedance Spectroscopy}

The electrochemical impedance was measured on the PICA/PPy composite electrode containing 10, 30 or $70 \%$ of PPy in the total mass of the active material. Prior to these measurements, the electrode was submitted to $10 \mathrm{CV}$ scans at $2 \mathrm{mV} \mathrm{s}^{-1}$. The impedance spectra obtained are presented in Figure 7. They are similar in shape and are representative of a capacitive behaviour. However, the imaginary component at $1 \mathrm{mHz}$ diminishes significantly with PPy content in agreement with the increase of the specific capacitance. Beside, the diameter of the high frequency semicircle decreases with increasing PPy content showing the decrease of the internal resistance which is essentially due to the charge transfer resistance at the active material/ separator interface.

\section{$<$ Figure $7>$}

These diagrams will be explained by the porous electrode behaviour with the equivalent electrical circuit shown on Figure 4. The values of the different elements obtained by regression calculation are listed in Table 7.

$<$ Table $7>$ 
From the data displayed in Table 7, it can be noticed that resistances $R_{\mathrm{S}}, R_{\mathrm{t}}$ and $R_{0}$ decrease whereas the double layer capacitance $C$ becomes greater when the PPy content in the composite film increases. The decrease of the total cell resistance $R_{\mathrm{c}}\left(R_{S}+R_{t}+R_{L}\right)$ with the increase of polypyrrole content substantiates an improved capacitive response. These results thus confirm those obtained with $\mathrm{CV}$.

\section{Complex capacitance}

As performed above, the experimental electrochemical impedance spectra were transformed into complex capacitances using Equation 15. The modulus of complex capacitance against frequency for PICA/PPy electrodes with PPy contents of 10, 30, or 70 mass - \% is plotted in Figure 8.

\section{$<$ Figure $8>$}

These capacitance spectra were then modelled with two relaxation phenomena according to Equation 18. The obtained parameters after the same fitting procedure (Simplex method) are listed in Table 8.

$<$ Table $8>$

From this table, one can readily note that the total capacitances are in a good agreement with the values obtained by CV (Figure SI-5), which validates the analysis methods employed here. Interestingly, these specific capacitance values reported in Table 8 can be predicted by using the composition of composite electrodes as well as the specific capacitance value of each of the two major components, i.e. $486 \mathrm{~F} \mathrm{~g}^{-1}$ for PPy and $83.6 \mathrm{~F} \mathrm{~g}^{-1}$ for PICA (see Table 3, PTFE neglected). The specific capacitance of the PICA/PPy with PPy content of $70 \%$ possesses the highest value. The increase of specific capacitance with the PPy mass $\%$ in the composite electrode material assesses that the PPy improves the performance of carbon/carbon supercapacitor. 
At this stage, a higher amount of PPy in the composite active material clearly increases the performances of the resulting supercapacitors by improving the specific capacitance, possibly as a consequence of a pseudo-capacitive behaviour of PPy resulting from its electroactivity. Nevertheless, it makes simultaneously the working potential range narrower and it leads to a slightly higher instability at least during the ten first CV scans and to a lower charge transfer resistance at the active material/separator interface. In the presence of such opposite effects on the supercapacitor performances, it appears necessary to optimize the amount of PPy powder in the composite PPy/PICA active materials of supercapacitor electrodes.

However, the cyclic voltammograms and also the capacitance changes presented in Figures SI-4 and SI-5 respectively showed as expected that the PPy takes part in the redox process, that is the higher capacitance obtained contains a part of the pseudo-capacitance. This system will therefore likely be subjected to a premature degradation. Besides, the effective operating voltage, if one would like to avoid too deep redox process of PPy, will become substantially narrower. Finally, as PPy is possibly more expensive than carbon powder, the cost effectiveness has to be taken into account. For all these reasons, the addition of a reasonable amount of $\mathrm{PPy}$, around a $10 \%$ mass percentage seems to be the best compromise.

\section{Conclusion}

A nanostructured polypyrrole powder was successfully synthesized chemically by using nanostructured $\mathrm{MnO}_{2}$ as oxidizing agent and nanostructured sacrificial template simultaneously. It was then used to improve the capacitive performances of (Swagelok type) carbon/carbon supercapacitor devices, as shown by means of cyclic voltammetry and electrochemical impedance spectroscopy. 
The PICA/PPy composite electrode exhibits a much higher specific capacitance than the PICA electrode, due to the addition of nanostructured PPy powder and to the improvement of contact resistance between carbon particles. The PICA/PPy electrode also shows a cycling stability similar to that of the PICA electrode and the increase of the mass percentage of PPy in the PICA electrode can improve significantly its specific capacitance. As a result, addition of an optimised amount of nanostructured PPy powder to high surface area activated carbon can improve the performance of carbon/carbon supercapacitors, but an excessive addition of PPy powder to carbon seems to induce a premature ageing of electrical storage device. Further investigations aimed at understanding how the specific area and the morphology of PPy affect the composite electrode capacitance are currently underway.

\section{Acknowledgements}

Drs P. Simon and P.-L. Taberna (CIRIMAT, UMR 5085, CNRS and Univ. Toulouse 3, CNRS, Toulouse, France) are warmly acknowledged for their support in the use of Swagelok type cell. The authors also thank efficient assistance of Dr. Cyrille BAZIN (LISE, UMR 8235) for XRD analyses. Co-authors thank French-Algerian cooperation project CMEP-PHC Tassili 06MDU686 for having funded this work. 


\section{References}

[1] S.R.S. Prabaharan, R. Vimala, Z. Zainal, J. Power Sources 161 (2006) 730-736.

[2] G.-M. Zhou, D.-W. Wang, F. Li, L.-L. Zhang, Z. Weng, H.-M. Cheng, New Carbon Mater. 26(3) (2011) 180-186.

[3] R. Richner, S. Müller, A. Wokaun, Carbon 40 (2002) 307-314.

[4] B.E. Conway, Electrochemical Supercapacitors, Kluwer Academic Publishers, New York, 1999.

[5] A. Burke, J. Power Sources 91 (2000) 37-50.

[6] D. Qu, H. Shi, J. Power Sources 74 (1998) 99-107.

[7] H. Chi-Chang, L. Wen-Yar, L. Jeng-Yan, J. Power Sources, 137 (2004) 152-157.

[8] E. Frackowiak, Phys. Chem. Chem. Phys., 9 (2007) 1774-1785.

[9] J. Gamby, P.L. Taberna, P. Simon, J.F. Fauvarque, M. Chesneau, J. Power Sources, 101(1), (2001), 109-116.

[10] S. Vaquero, J. Palma, M. Anderson, R. Marcilla, Int. J. Electrochem. Sci., 8(8) (2013) 10293-10307.

[11] R. Holze, Y.P. Wu, Electrochim. Acta, 122 (2014) 93-107

[12] J-G. Wang, Y. Yang, Z-H. Huang, F. Kang, J. Mater. Chem. 22 (2012) 16943-16949.

[13] C-C. Hu, W-Y. Li, J-Y. Lin, J. Power Sources 137 (2004) 152-157.

[14] Q. Wang, J.L. Li, F. Gao, W.S. Li, Kz. Wu, X.D. Wang, New Carbon Mater. 23(3) (2008) $275-280$.

[15] H. Mi, X. Zhang, X. Ye, S. Yang, J. Power Sources 176 (2008) 403-409.

[16] D.P. Dubal, S.H. Lee, J.G. Kim, W.B. Kim, C.D. Lokhande, J. Mater. Chem. 22 (2012) 3044-3052.

[17] M.A. Smit, A.L. Ocampo, M.A. Espinosa-Medina, P.J. Sebastian, J. Power Sources 124 (2003) 59-64. 
[18] A. Laforgue, P. Simon, J.-F. Fauvarque, J. Electrochem. Soc., 148(10) (2001) A11301134.

[19] A. Laforgue, P. Simon, J.-F. Fauvarque, J. Electrochem. Soc., 150 (5) (2003) A645-651.

[20] F.L. Zhang, T. Nyberg, O. Inganas, Nano Lett. 2 (2002) 1373-1377.

[21] L. Dauginet-Da Pra, S. Demoustier-Champagne, Polymer 46 (2005) 1583-1594.

[22] C.R. Martin, Science, 266 (1994) 1961-1966.

[23] J. Jang, H. Yoon, Chem. Commun., 6 (2003) 720-721.

[24] M.X. Wan, K. Huang, L.J. Zhang, Int. J. Nonlinear Sci. Numer. Simul. 3 (3-4) (2002) 465-468.

[25] V. Gupta, N. Miura, Electrochem. Solid-State Lett. 8(12) (2005) A630-A632.

[26] C. Arbizzani, M. Mastragostino, L. Menegheta, Electrochim. Acta 41 (1996) 21-26.

[27] P. Azaïs, L. Duclaux, P. Florian, D. Massiot, M.A. Lillo-Rodenas, A. Linares-Solano, J-P. Peres, C. Jehoulet, F. Béguin, J. Power Sources 171 (2007) 1046-1053.

[28] R. Kötz, M. Carlen, Electrochim. Acta 45 (2000) 2483-2498.

[29] H. Mi, X. Zhang, Y. Xu, F. Xiao; Appl. Surface Sci. 256(7) (2010) 2284-2288.

[30] D. Zhang, X. Zhang, Y. Chen, P. Yu, C. Wang, Y. Ma; J. Power Sources 196(14) (2011) 5990-5996.

[31] X. Lu, F. Zhang, H. Dou, C. Yuan, S. Yang, L. Hao, L. Shen, L. Zhang, X. Zhang; Electrochim. Acta 69 (2012) 160-166.

[32] X. Lu, H. Dou, C. Yuan, S. Yang, L. Hao, F. Zhang, L. Shen, L. Zhang, X. Zhang; J. Power Sources, 197 (2012) 319-324.

[33] S. Ye, J. Feng, ACS Appl. Mater. Interfaces, 6, (2014), 9671-9679.

[34] J. Zhang, X.S. Zhao, J. Phys. Chem. C, 116 (2012), 5420-5426.

[35] L. Benhaddad, M.C. Bernard, C. Deslouis, L. Makhloufi, B. Messaoudi, A. Pailleret, H. Takenouti, Synth. Met. 175 (2013) 192-199. 
[36] S. Vaquero, R. Diaz, M. Anderson, J. Palma, R. Marcilla, Electrochim. Acta 86 (2012) 241-247.

[37] L. Benhaddad, L. Makhloufi, B. Messaoudi, K. Rahmouni and H. Takenouti, J. Mater. Sci. Technol. 27 (2011) 585-593.

[38] L. Benhaddad, L. Makhloufi, B. Messaoudi, K. Rahmouni and H. Takenouti, ACS Appl. Mater. Interfaces 1 (2009) 424-432.

[39] H. Zhang, X. Zhong, J.J. Xu , H.Y. Chen, Langmuir 24 (2008) 13748-13752.

[40] J. Li, L. Cui, X. Zhang, Appl. Surf. Sci. 256 (2010) 4339-4343.

[41] Y. Zhang, H. Feng, X. Wu, L. Wang, A. Zhang, T. Xia, H. Dong, X. Li, L. Zhang, Int. J. Hydrogen Energy 34 (11) (2009) 4889-4899.

[42] H. Mi, X. Zhang, X. Ye, S. Yang, J. Power Sources 176 (2008) 403-409.

[43] J. Yan, Z. Fan, T. Wei, W. Qian, M. Zhang, F. Wei, Carbon 48 (2010) 3825-3833.

[44] J. Li, H. Xie, Mater. Lett., 78 (2012) 106-109.

[45] P. Diard, B. Le Gorrec, C. Montella, Handbook of Electrochemical Impedance Spectroscopy; Diffusion impedance, Bio-Logic 2012 Claix (near Grenoble), France

[46] R. de Levie, Electrochim. Acta 8 (1963) 751-780.

[47] J. Newman, C.W. Tobias, J. Electrochem. Soc. 109 (1962) 1183-1191.

[48] C. Largeot, C. Portet, J. Chmiola, P-L. Taberna, Y. Gogotsi, P. Simon, J. Am. Chem. Soc. 130(9) (2008) 2730-2731.

[49] P.L. Taberna, P. Simon, J.F. Fauvarque, J. Electrochem. Soc. 150 (2003) A292-A300.

[50] A.G. Pandolfo, A.F. Hollenkamp, J. Power Sources 157 (2006) 11-27.

[51] G.J. Brug, A.L.G. Van Den Eeden, M. Sluyters-Rehbach, J.H. Sluyters, J. Electroanal. Chem. 176 (1984) 275-295. 

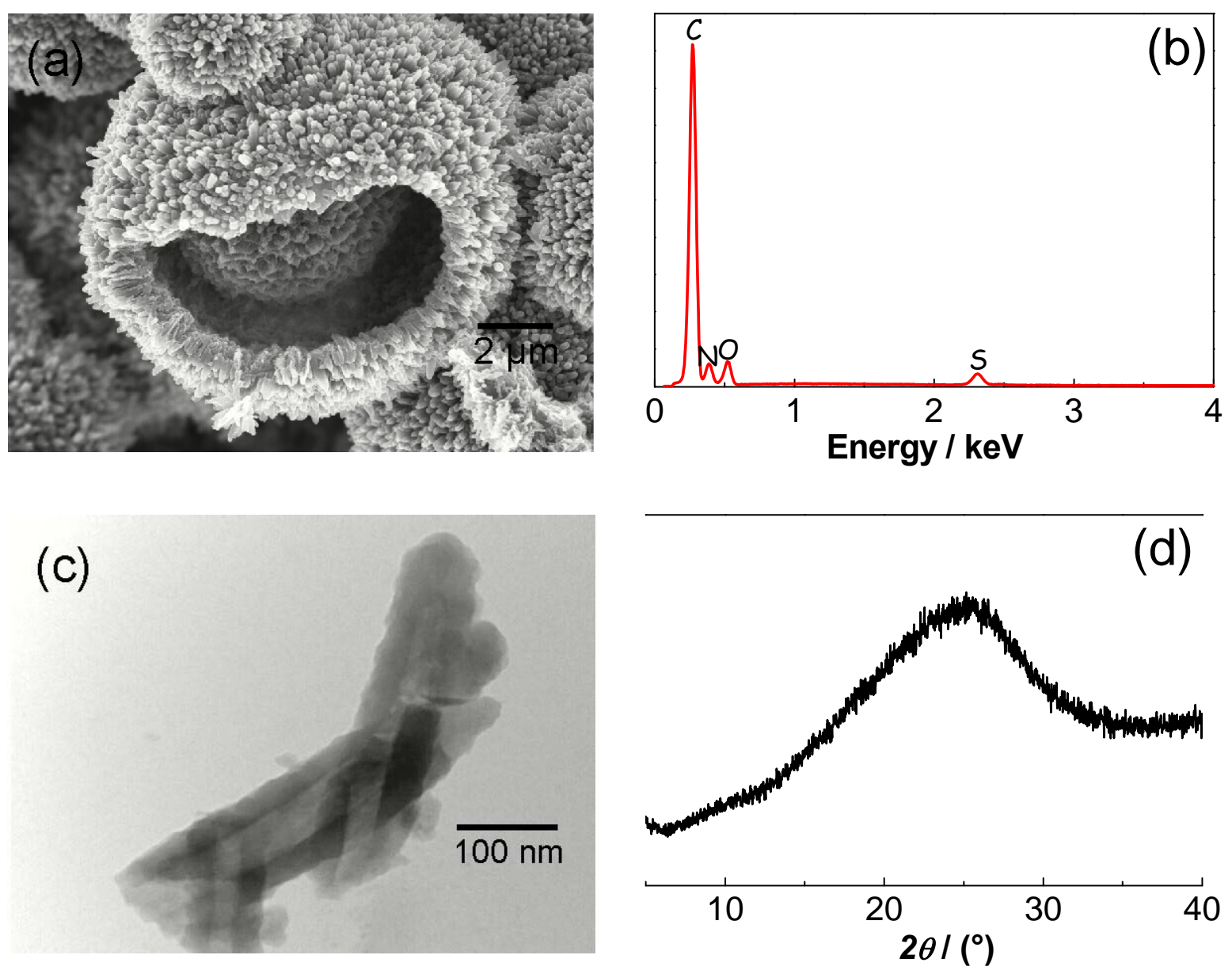

Figure 1. (a) FEG-SEM image and (b) EDX profile, (c) TEM image after grinding, and (d) XRD pattern of synthesized polypyrrole powder 

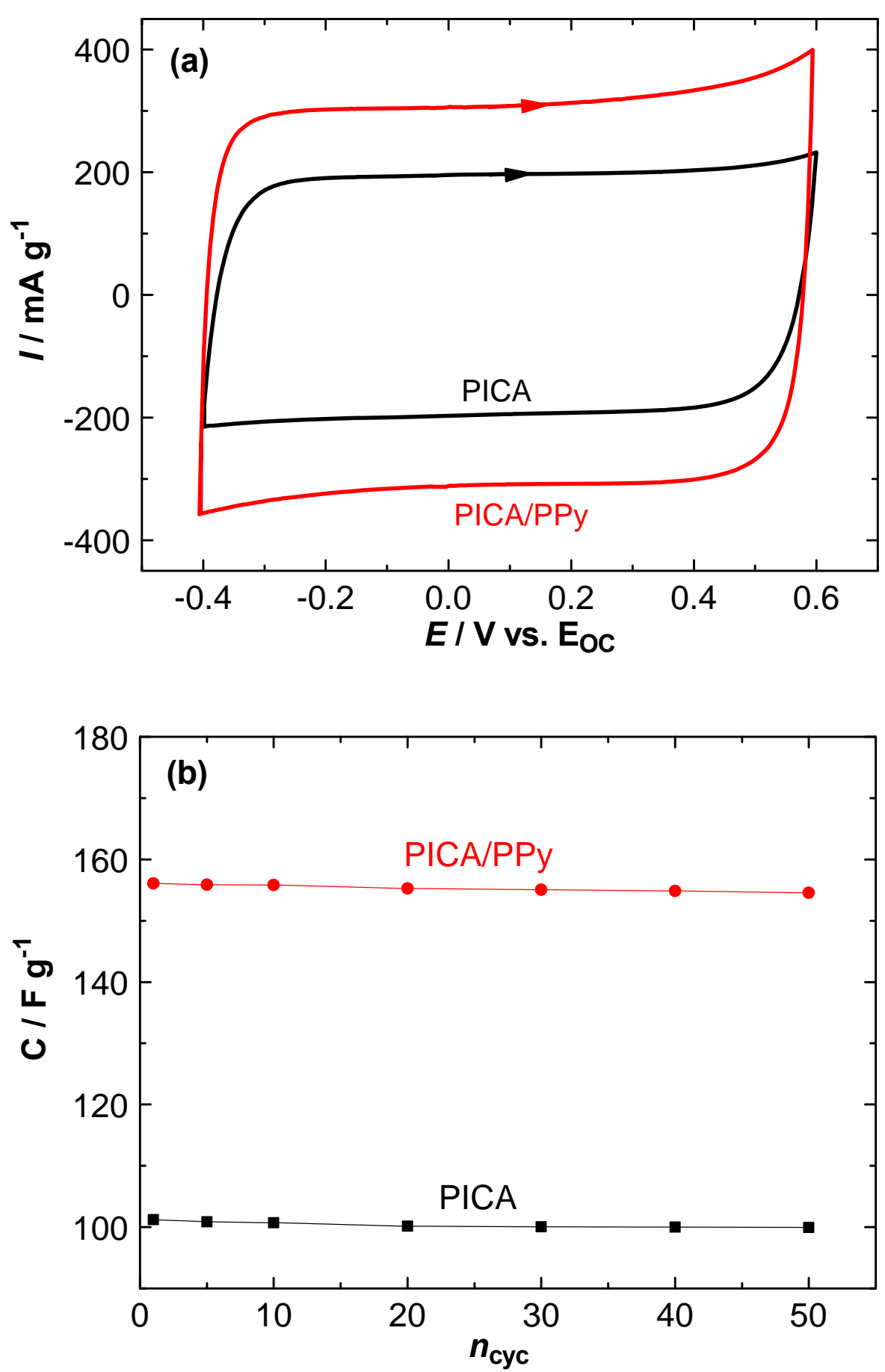

Figure 2. (a) Cyclic voltammograms of PICA and PICA/PPy electrodes at a $2 \mathrm{mV} \mathrm{s}^{-1}$ scan rate. The separator was impregnated with a $1 \mathrm{M} \mathrm{NaNO}_{3}$ aqueous electrolytic solution, (b) Evolution of the specific capacity of PICA and PICA/PPy electrodes as a function of the number of cyclic potential scans 


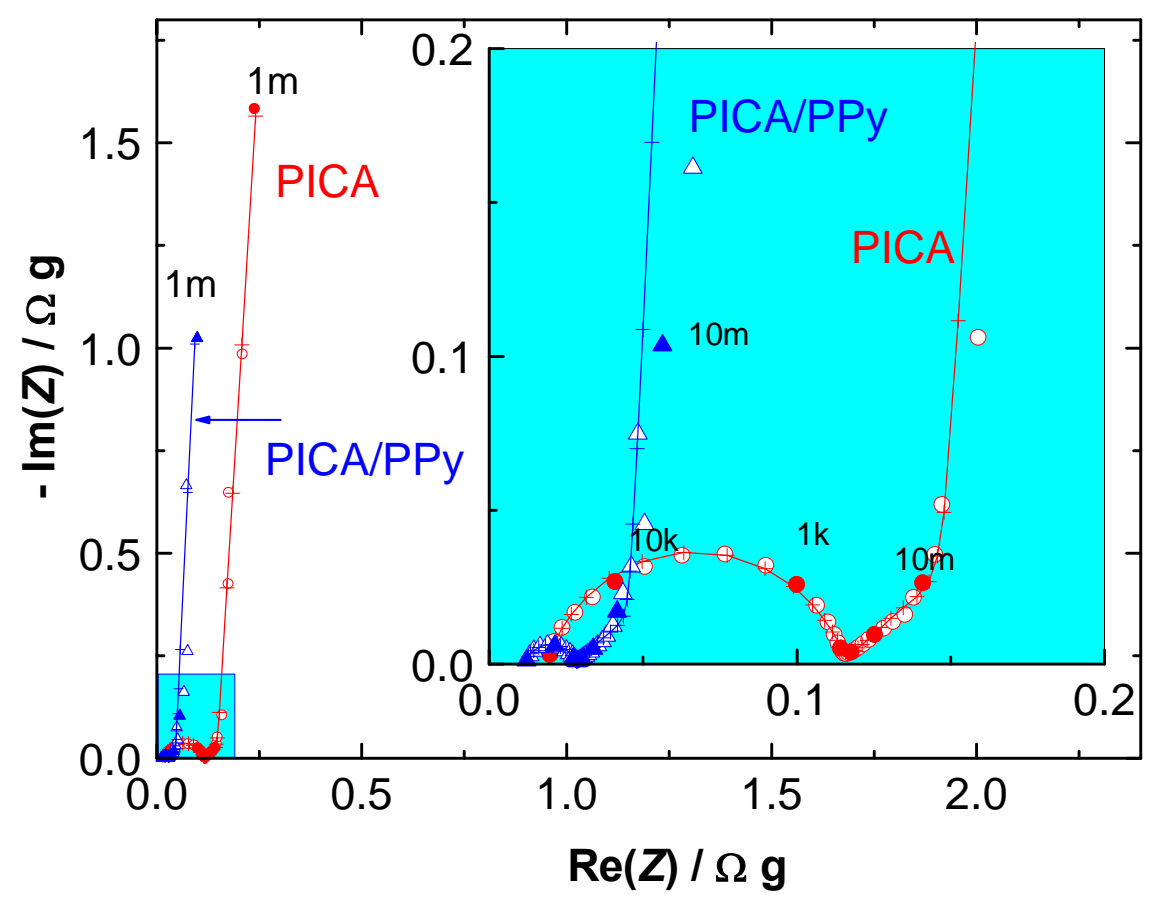

Figure 3. Comparison of the experimental EIS spectrum with the one calculated with the porous electrode model. The insert shows the HF part in enlarged scale (blue triangles and red circles : experimental data for PICA/PPy and PICA electrodes respectively, and + : calculated data with same color code)

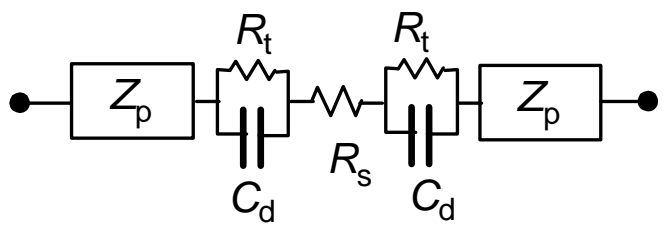

Figure 4. Equivalent electrical circuit for a porous electrode behaviour 

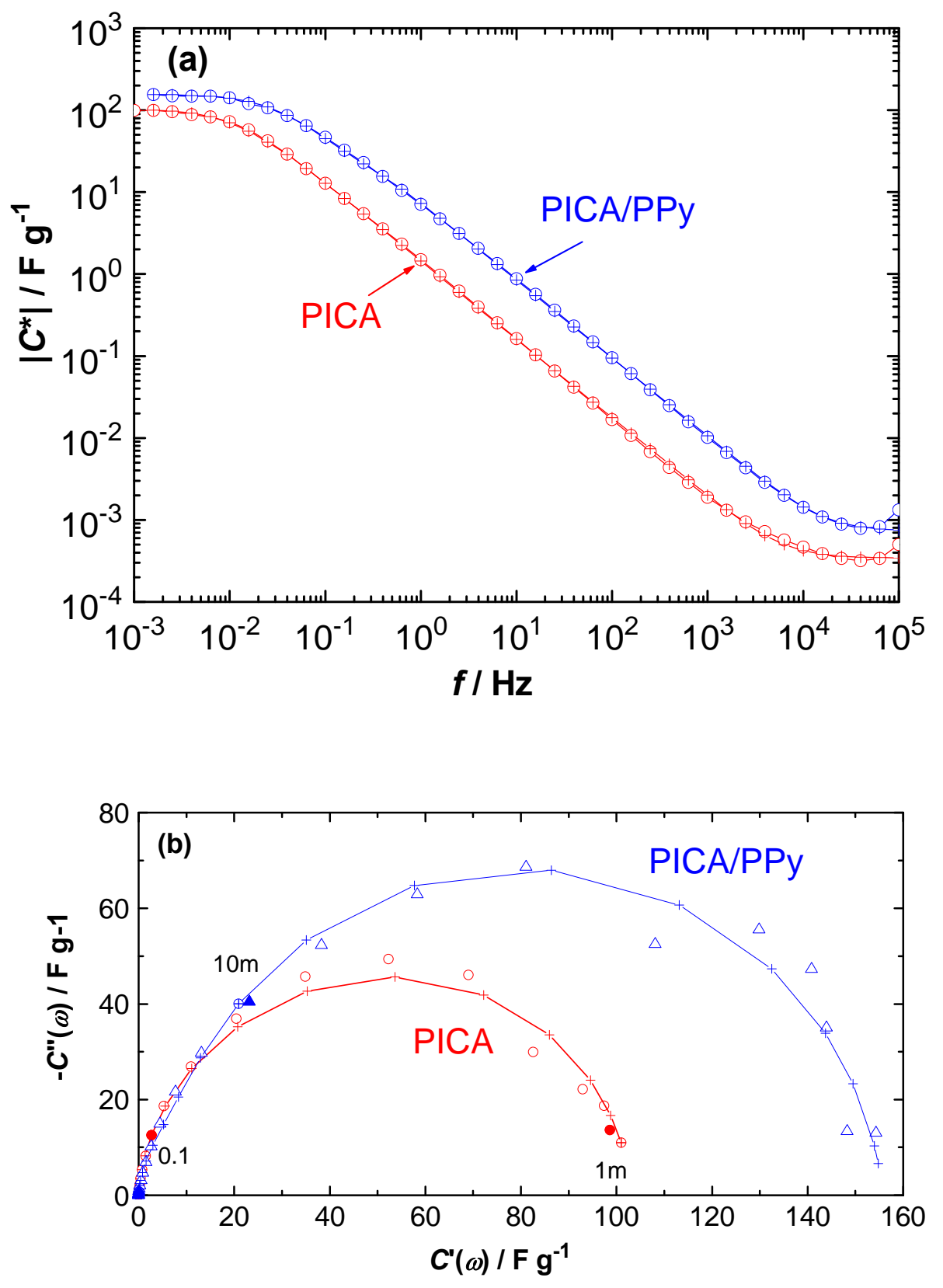

Figure 5. Evolution of the complex capacitance modulus as a function of frequency for the PICA (in red) and PICA/PPy (in blue) (a) Bode-type plot (b) Cole-Cole plot 

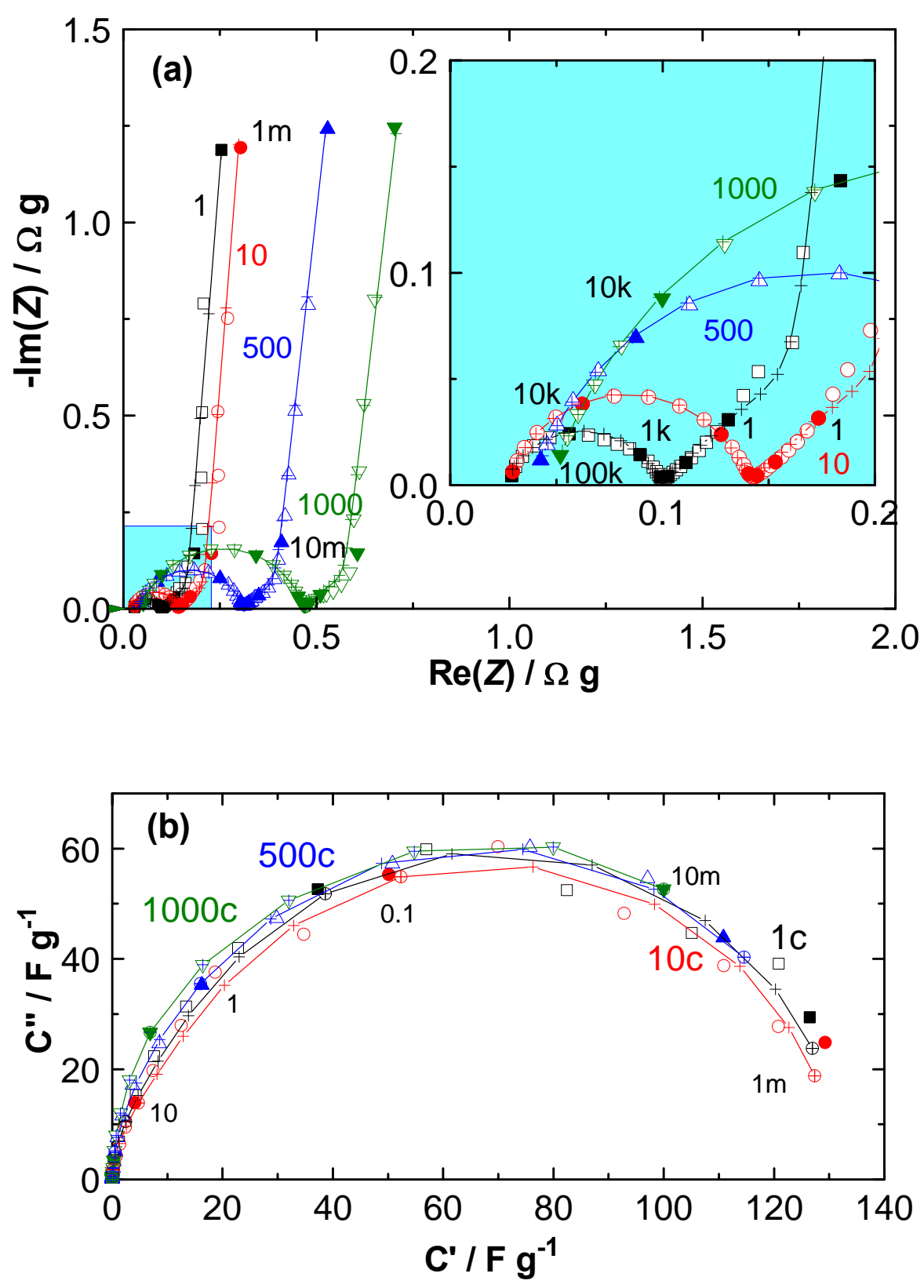

Figure 6. Ageing effect by potential cycling on the EIS spectra of PICA/PPy electrodes : (a) Nyquist-type plot (b) Cole-Cole plot 


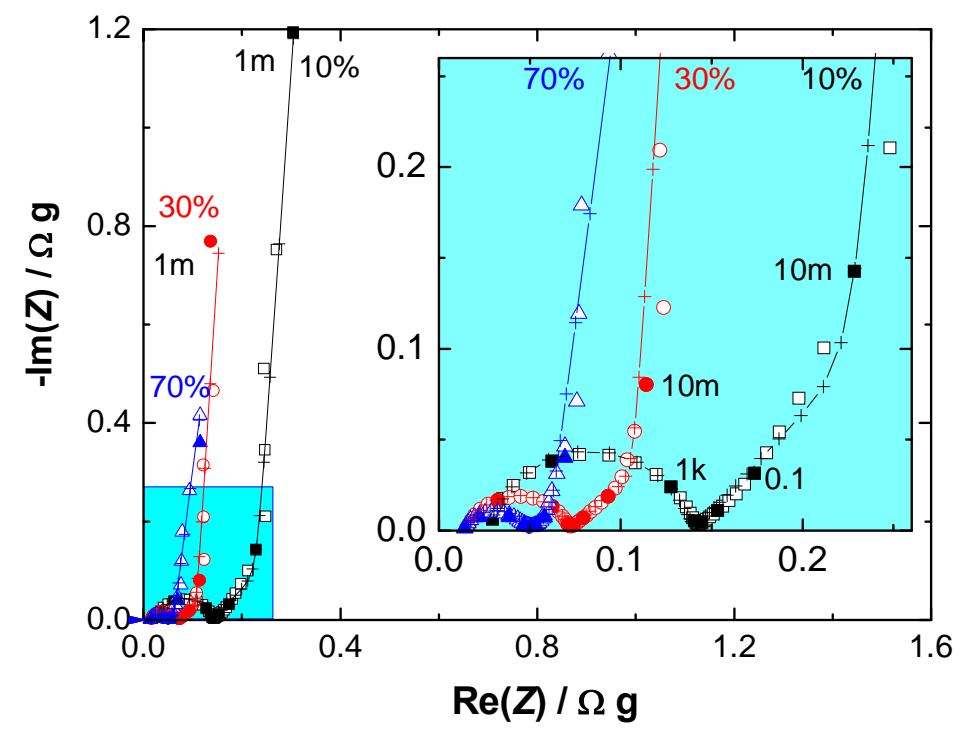

Figure 7. Comparison of the experimental impedance spectrum (experimental data) with the one calculated with the de Levie model for PICA / PPy electrodes for different mass percentages of PPy. The insert shows the HF part in enlarged scale (blue triangles and red circles : experimental data for PICA/PPy and PICA electrodes respectively, and + : calculated data with same color code)

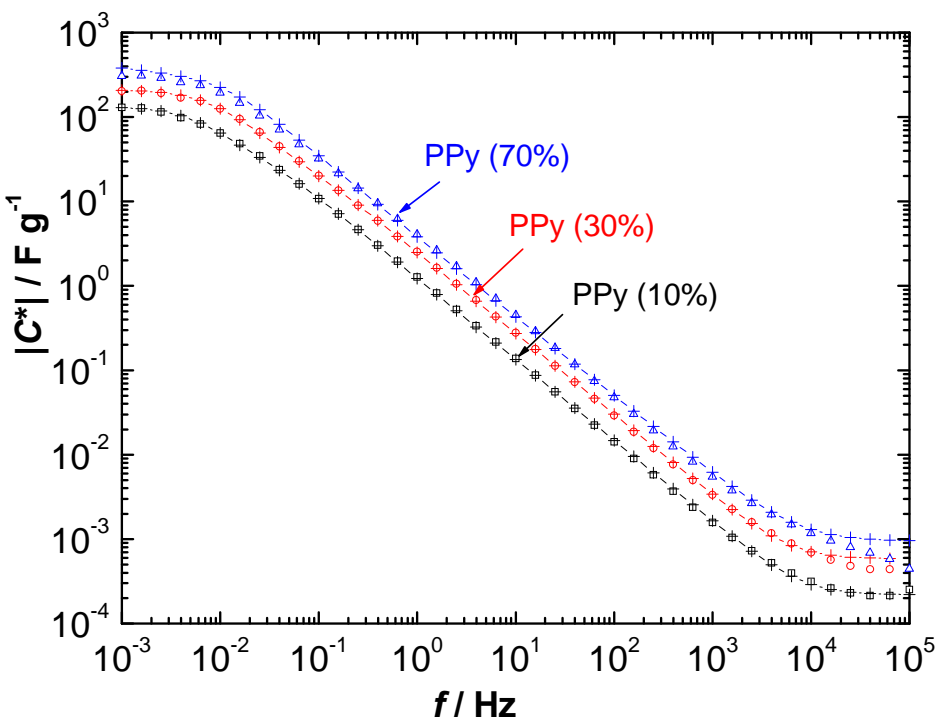

Figure 8. Evolution of the modulus of cell complex capacitance as a function of frequency for PICA / PPy electrodes with different mass percentages of PPy 
Table 1. Specific capacitance values of composite supercapacitor electrodes based on polypyrrole and carbon materials.

\begin{tabular}{|c|c|c|c|c|}
\hline Electrodes & Electrolyte & Conditions & $\begin{array}{c}\text { Capacitance } \\
\qquad\left(\mathrm{F} \mathrm{g} \mathrm{g}^{-1}\right)\end{array}$ & Ref \\
\hline $\begin{array}{l}\text { PPy/carbon nanotubes } \\
\text { PPy/CNT }\end{array}$ & $\mathrm{KCl}(1 \mathrm{M})$ & $1 \mathrm{~mA} \mathrm{~cm}^{-2}$ & 304 & {$[29$} \\
\hline \multicolumn{5}{|l|}{ PPy/graphite } \\
\hline \multirow[t]{2}{*}{ PPy/Graphite } & \multirow{4}{*}{$\mathrm{H}_{2} \mathrm{SO}_{4}(1 \mathrm{M})$} & $0.5 \mathrm{Ag}^{-1}$ & 482 & \multirow{4}{*}[30]{} \\
\hline & & $5 \mathrm{Ag}^{-1}$ & 222 & \\
\hline \multirow[t]{2}{*}{ PPy } & & $0.5 \mathrm{Ag}^{-1}$ & 152 & \\
\hline & & $5 \mathrm{Ag}^{-1}$ & 43 & \\
\hline \multicolumn{5}{|l|}{ CNT/Graphite/PPy } \\
\hline PPy/Graphite & \multirow{3}{*}{$\mathrm{KCl}(1 \mathrm{M})$} & \multirow{3}{*}{$0.2 \mathrm{~A} \mathrm{~g}^{-1}$} & 265 & \multirow{3}{*}[31]{} \\
\hline CNT/PPy & & & 253 & \\
\hline CNT/Graphite/PPy & & & 361 & \\
\hline \multicolumn{5}{|l|}{ CNT/PPy/Graphite } \\
\hline Graphite & \multirow{3}{*}{$\mathrm{KCl}(1 \mathrm{M})$} & \multirow{3}{*}{$0.2 \mathrm{~A} \mathrm{~g}^{-1}$} & 73 & \multirow{3}{*}{32} \\
\hline PPy/CNT & & & 164 & \\
\hline CNT/PPy/Graphite & & & 211 & \\
\hline \multicolumn{5}{|l|}{ PPy/Graphene } \\
\hline PPy NTs & \multirow{3}{*}{$\mathrm{H}_{2} \mathrm{SO}_{4}(1 \mathrm{M})$} & \multirow{3}{*}{$0.5 \mathrm{~A} \mathrm{~g}^{-1}$} & 144 & \multirow{3}{*}{ [33] } \\
\hline Graphene aerogel & & & 180 & \\
\hline Graphene/Polypyrrole aerogel & & & 253 & \\
\hline \multicolumn{5}{|l|}{ RGO/PPy } \\
\hline \multirow[t]{4}{*}{ RGO/PPy } & & $0.3 \mathrm{Ag}^{-1}$ & 249 & \multirow{4}{*}{ [34] } \\
\hline & & $0.5 \mathrm{Ag}^{-1}$ & 229 & \\
\hline & & $1.0 \mathrm{~A} \mathrm{~g}^{-1}$ & 204 & \\
\hline & & $2.0 \mathrm{~A} \mathrm{~g}^{-1}$ & 189 & \\
\hline
\end{tabular}

Table 2. Values of the parameters obtained by the diffusion model

\begin{tabular}{|c|c|c|c|c|c|c|c|c|}
\hline Electrode & $\begin{array}{l}D \times 10^{9} \\
\mathrm{~cm}^{2} \mathrm{~s}^{-1}\end{array}$ & $\begin{array}{c}\delta \\
\mu \mathrm{m}\end{array}$ & $n_{\mathrm{D}}$ & $\begin{array}{c}R_{\mathrm{s}} \\
\Omega \mathrm{cm}^{2}\end{array}$ & $\begin{array}{c}R_{\mathrm{t}} \\
\Omega \mathrm{cm}^{2}\end{array}$ & $\begin{array}{c}C_{\mathrm{d}} \\
\mu \mathrm{F} \mathrm{cm}-2\end{array}$ & $n_{c}$ & $\begin{array}{l}\chi \\
\%\end{array}$ \\
\hline PICA & 1.94 & 1.28 & 0.96 & 1.59 & 8.17 & 31.9 & 0.824 & 2.55 \\
\hline PICA/PPy & 2.61 & 1.24 & 0.953 & 1.59 & 2.11 & 24.7 & 0.879 & 2.55 \\
\hline
\end{tabular}


Table 3. Values of the equivalent electrical circuit elements for the de Levie model.

\begin{tabular}{|c|c|c|c|c|c|c|c|c|c|c|}
\hline Electrode & $\begin{array}{c}L^{*} \\
\mathrm{~mm}\end{array}$ & $\begin{array}{c}R_{S} \\
\mathrm{~m} \Omega \mathrm{g}\end{array}$ & $\begin{array}{c}R_{t} \\
\mathrm{~m} \Omega \mathrm{g}\end{array}$ & $\begin{array}{c}C_{d} \\
\mu F g^{-1}\end{array}$ & $a_{t}$ & $\begin{array}{l}R_{0} \\
\Omega \mathbf{g}\end{array}$ & $\begin{array}{c}Q \\
F g^{-1} \mathbf{s}^{\mathrm{a}-1}\end{array}$ & $a$ & $\begin{array}{c}R_{\mathbf{l}} \\
\mathrm{m} \Omega \mathrm{g}\end{array}$ & $\begin{array}{l}\chi \\
\%\end{array}$ \\
\hline PICA & 1.7 & 18.7 & 96.1 & 469 & 0.82 & 0.55 & 83.6 & 0.96 & 115 & 2.24 \\
\hline PICA/PPy & 1.5 & 12 & 15.9 & 848 & 0.87 & 0.34 & 136 & 0.97 & 28.1 & 2.67 \\
\hline
\end{tabular}

*Fixed value

Table 4. The specific complex capacitance of PICA and PICA / PPy electrodes.

\begin{tabular}{lccccccccc}
\hline Electrode & $\begin{array}{c}\boldsymbol{C}_{0} \\
\boldsymbol{\mu} \mathbf{F ~ g}^{-1}\end{array}$ & $\begin{array}{c}\boldsymbol{C}_{\mathbf{1}} \\
\mathbf{F ~ g}^{-1}\end{array}$ & $\begin{array}{l}\boldsymbol{t}_{1} \\
\mathbf{s}\end{array}$ & $\mathbf{a}_{1}$ & $\begin{array}{c}\boldsymbol{C}_{2} \\
\mathbf{F ~ g}^{-1}\end{array}$ & $\begin{array}{c}\boldsymbol{t}_{2} \\
\mathbf{s}\end{array}$ & $\mathbf{a}_{2}$ & $\begin{array}{c}\boldsymbol{C}_{\text {total }} \\
\mathbf{F ~ g}^{-1}\end{array}$ & $\begin{array}{c}\chi \\
\%\end{array}$ \\
\hline PICA & 452 & 1 & 0.85 & 1.00 & 100 & 14.3 & 0.97 & 101 & 5.6 \\
\hline PICA/PPy & 662 & 7.6 & 0.47 & 0.98 & 146 & 5.8 & 0.94 & 154 & 3.41 \\
\hline
\end{tabular}

Table 5. Values of the equivalent electrical circuit elements for ageing experiments.

\begin{tabular}{|c|c|c|c|c|c|c|c|c|c|c|}
\hline Cycles & $\begin{array}{c}L^{*} \\
\mathrm{~mm}\end{array}$ & $\begin{array}{c}R_{S} \\
\mathrm{~m} \Omega \mathrm{g}\end{array}$ & $\begin{array}{c}R_{t} \\
\mathrm{~m} \Omega \mathrm{g}\end{array}$ & $\begin{array}{c}C_{d} \\
\mu F g^{-1}\end{array}$ & $a_{t}$ & $\begin{array}{c}R_{0} \\
\Omega \mathbf{g}\end{array}$ & $\begin{array}{c}Q \\
F g^{-1} s^{a-1}\end{array}$ & $a$ & $\begin{array}{c}R_{\mathbf{l}} \\
\mathrm{m} \Omega \mathrm{g}\end{array}$ & $\begin{array}{l}\chi \\
\%\end{array}$ \\
\hline 1 & 1.8 & 26 & 70.7 & 335 & 0.8 & 0.94 & 92 & 0.93 & 98 & 2.74 \\
\hline 10 & 1.8 & 27 & 111 & 273 & 0.84 & 0.97 & 91.6 & 0.92 & 139 & 2.15 \\
\hline 500 & 1.8 & 38 & 269 & 207 & 0.81 & 1.4 & 91.4 & 0.93 & 308 & 1.38 \\
\hline 1000 & 1.8 & 47.1 & 419 & 190 & 0.81 & 1.7 & 90 & 0.93 & 467 & 1.4 \\
\hline
\end{tabular}

*Fixed value 
Table 6. Variation of the specific complex capacitance with respect to the number of cyclic potential scans.

\begin{tabular}{rccccccccc}
\hline Cycles & $\begin{array}{c}\boldsymbol{C}_{0} \\
\boldsymbol{\mu} \mathrm{F} \mathrm{g}^{-1}\end{array}$ & $\begin{array}{c}\boldsymbol{C}_{1} \\
\mathbf{F ~ g}^{-1}\end{array}$ & $\begin{array}{c}\boldsymbol{t}_{1} \\
\mathbf{s}\end{array}$ & $\mathbf{a}_{1}$ & $\begin{array}{c}\boldsymbol{C}_{2} \\
\mathrm{~F} \mathrm{~g}^{-1}\end{array}$ & $\begin{array}{c}\boldsymbol{t}_{2} \\
\mathbf{s}\end{array}$ & $\mathbf{a}_{2}$ & $\begin{array}{c}\boldsymbol{C}_{\text {total }} \\
\mathbf{F ~ g ~}^{-1}\end{array}$ & $\begin{array}{c}\chi \\
\%\end{array}$ \\
\hline 1 & 253 & 7.28 & 2.00 & 1.00 & 125 & 22.3 & 0.935 & 132 & 3.71 \\
10 & 230 & 6.93 & 3.20 & 1.00 & 127 & 29.4 & 0.952 & 133 & 3.36 \\
500 & 165 & 6.52 & 10.7 & 1.00 & 126 & 57.8 & 0.959 & 133 & 4.53 \\
\hline 1000 & 142 & 2.37 & 8.84 & 0.867 & 123 & 70.1 & 1.00 & 124 & 4.78 \\
\hline
\end{tabular}

Table 7. Values of the equivalent electrical circuit elements of PICA/PPy electrodes for different mass percentages of PPy.

\begin{tabular}{|c|c|c|c|c|c|c|c|c|c|c|}
\hline $\begin{array}{l}\text { PPy } \\
(\%)\end{array}$ & $\begin{array}{c}L^{*} \\
\mathrm{~mm}\end{array}$ & $\begin{array}{c}R_{S} \\
\mathrm{~m} \Omega \mathrm{g}\end{array}$ & $\begin{array}{c}R_{t} \\
\mathrm{~m} \Omega \mathrm{g}\end{array}$ & $\begin{array}{c}C_{d} \\
\mu F g^{-1}\end{array}$ & $a_{t}$ & $\begin{array}{l}R_{0} \\
\Omega \mathrm{g}\end{array}$ & $\begin{array}{c}Q \\
F g^{-1} s^{a-1}\end{array}$ & $a$ & $\begin{array}{c}R_{L} \\
\mathrm{~m} \Omega \mathrm{g}\end{array}$ & $\begin{array}{l}\chi \\
\%\end{array}$ \\
\hline 10 & 1.8 & 27 & 11 & 273 & 0.84 & 0.97 & 91.6 & 0.92 & 139 & 2.15 \\
\hline 30 & 1.5 & 14.8 & 57 & 629 & 0.76 & 0.67 & 174 & 0.96 & 72 & 1.97 \\
\hline 70 & 1.5 & 13.2 & 35 & 1560 & 0.7 & 0.24 & 257 & 0.92 & 48 & 1.99 \\
\hline
\end{tabular}

* Fixed value

Table 8. Variation of the specific complex capacitance of different PICA/PPy electrodes for different mass percentages of PPy

\begin{tabular}{|c|c|c|c|c|c|c|c|c|c|}
\hline $\begin{array}{l}\text { PPy } \\
(\%)\end{array}$ & $\begin{array}{c}C_{0} \\
\mu F g^{-1}\end{array}$ & $\begin{array}{c}C_{1} \\
\mathrm{~F} \mathrm{~g}^{-1}\end{array}$ & $\begin{array}{l}t_{1} \\
\mathrm{~s}\end{array}$ & $a_{1}$ & $\begin{array}{c}C_{2} \\
\mathrm{~F} \mathrm{~g}^{-1}\end{array}$ & $\begin{array}{l}t_{2} \\
\mathrm{~s}\end{array}$ & $a_{2}$ & $\begin{array}{l}C_{\text {total }} \\
\mathrm{F} \mathrm{g}^{-1}\end{array}$ & $\begin{array}{l}\chi \\
\%\end{array}$ \\
\hline 10 & 242 & 6.9 & 3.1 & 1.00 & 126 & 28.9 & 0.95 & 133 & 3.2 \\
\hline 30 & 712 & 6.64 & 1.52 & 0.93 & 210 & 20.8 & 0.99 & 217 & 2.8 \\
\hline 70 & 1020 & 5.21 & 1.07 & 1.00 & 312 & 19.7 & 0.95 & 317 & 3.2 \\
\hline
\end{tabular}

